\title{
Problem solution as a guided activity with Mexican schoolchildren
}

\author{
Yulia Solovieva $^{\mathrm{a}^{*}}$, Yolanda Rosas-Rivera ${ }^{\mathrm{b}}$, Luis Quintanar-Rojas ${ }^{\mathrm{a}}$

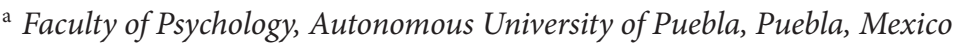 \\ ${ }^{\mathrm{b}}$ University Iberoamerican of Puebla, Puebla, Mexico \\ *Corresponding author. E-mail: yulia.solovieva@correo.buap.mx
}

\begin{abstract}
The goal of the present study was to describe the organization of a guided activity for problem solution in primary school. The method, which was applied to mathematical problems, allowed us to propose a specific orientation for the proper solution of arithmetic problems by pupils. The study was based on the activity-theory approach applied to the process of teaching and learning. It was carried out with pupils in the second grade of a private school in the city of Puebla (Mexico). The method was used in the classroom during 30 school sessions of 1 hour per day. The methodology of formative experiment was used in the study. Qualitative analysis of the pedagogical process of teaching and learning was conducted. The results show that, after participation in the formative process, the schoolchildren became able to identify essential elements, data, and all relationships among them in order to solve mathematical problems. At the end of the program the verbal external level was raised for the process of orientation and the solution of problems together with the ability to use logarithms independently. We conclude that orientation, as a guided form of activity in primary school, is essential for the development of the ability to analyze problems.
\end{abstract}

Keywords: problem solution, learning of mathematics, teaching methods, school age, orientation in mathematics, conceptual learning

\section{Introduction}

In Mexico, the teaching of mathematics in primary school faces severe difficulties. The learning of school pupils is extremely poor. The results of national tests show that only $39.5 \%$ of the pupils in the sixth grade show a sufficient level of knowledge of mathematics (Planea, 2015). Similar results were obtained during the Second Regional Comparative and Explanatory Study of pupils in Mexico and other countries of Latin America: it was found that $30 \%$ of the children did not understand the meaning of the decimal system and were not able to perform elementary arithmetic operations (SERCE, 2009). Similar problems are typical also in other countries. 
Spanish authors Vicente, Dooren, and Verschaffel (2008), while analyzing results from the OECD Programme for International Student Assessment (PISA), found that for Spanish pupils the worst results were obtained for problem solution. Such results indicate that the children need not only to memorize some kinds of knowledge but also to develop the ability to use concepts in problems with mathematical situations. The weak areas of teaching in primary school are instilling an understanding of the concept of number, an ability to execute operations, and the capability to solve problems.

The same kind of necessity for organized work with the content of concepts instead of isolated memorization and execution of operations has been claimed by representatives of the activity-theory approach (Galperin, 1959a/2011; Davídov, 1988; Ilienkov, 2009; Talizina, 2009). Nowadays, such work is still necessary within the teaching process and programs of education in many countries. The traditional way of organizing the teaching and learning process is no longer useful in the modern world. There are two main types of teaching and learning activity. The first one might be called the traditional education system, in which the empirical process of teaching and learning takes place without specific consideration of systems of knowledge and abilities to teach. The spontaneous acquisition of knowledge is the result of such a system with no gains in conceptual knowledge or with problem solution. Within this system of education, there are no clear goals for the formation of concepts. The goals are related only to concrete operations, which are limited to the accumulation of habits. The goal of teaching mathematics is to execute arithmetical operations and to memorize symbols from only a formal point of view. The basic method is repetition of enormous numbers of exercises of the same type (Ávila, 2006; Bermejo, 2008; Martín, 2003). Normally, this kind of teaching of mathematics is boring for children, and the results are extremely poor.

The second type of education is almost absent in official educational programs in Latin America, as in other countries, but it appears as a kind of innovative research program by psychologists and pedagogues in different contexts. Often, programs of this type are the results of experimental research initiated and directed by specialists in the sphere of education (Salmina, 2001; De Zubiría, 2006; Talizina, 2009; Solovieva \& Quintanar, 2010; Solovieva, 2013; Solovieva, Lázaro, Rosas, Quintanar, Escotto, \& Sánchez, 2014[). Such programs are based on the so-called social-cultural approach directed by a constructivist perspective (Carretero \& Castorina, 2012). In other studies, the research takes into account the systematic backgrounds of activity theory (Rosas, Solovieva, \& Quintanar, 2014; Solovieva, Lázaro, \& Quintanar, 2013; Solovieva, Ortiz, \& Quintanar, 2010; Talizina, 2000; Zárraga, Quintanar, García, \& Solovieva, 2012).

Special research has been carried out not only with the goal of assessment and confirmation of difficulties of pupils, but as a way of presenting knowledge within oriented actions in order to guarantee the successful formation of concepts (Nikola \& Talizina, 2001; Salmina, 2001; Volodarskaya, 2001). Such methods for the initial formation of actions on a materialized level with posterior interiorization were proposed for the development of number-concept, decimal-system, and basic logic operations such as measuring, comparing, and converting (Salmina \& Filimonova, 2010; Solovieva, Ortíz, \& Quintanar, 2010; Solovieva, Rosas, \& Quintanar, 2013; 
Talizina, 2009; Zárraga, Quintanar, García, \& Solovieva, 2012). In order to achieve positive acquisition of concepts and logical intellectual actions, the teacher needs to understand the structure of the content to be taught, the intellectual actions proposed for the children, and the organization of the gradual interiorization of the actions by stages: materialized, perceptual, verbal external, and verbal internal (Galperin, 1957; Álvarez \& Del Río, 2013; Nikola \& Talizina, 2001; Solovieva, 2013; Talizina, 2009).

In the case of problem solution, its content is not limited by the traditional topics taught in elementary mathematics. Nikola y Talizina (2001) has stressed that the content of problems involves the category of processes, which is never presented or explained to children. At the same time, problem solutions represent a kind of intellectual action, in which mathematical concepts and operations can actually be applied without memorization. This cognitive activity requires understanding not only the content of arithmetic but also the elements of a symbolic situation and the relations among these elements (Vicente et al., 2008). Children cannot understand these relationships spontaneously or individually but require specific, guided orientation (Galperin, 1959b/2011).

Traditional teaching usually does not present the content (internal image) of the problem situation but simply "asks" the final question of the problem. The question of the problem does not appear in the consciousness of the pupil as a mathematical question, which requires mathematical actions and solutions, but only as any kind of question in day-to-day life. In such a case no reflection or understanding takes place in the consciousness of the child. Children act in a chaotic, nonsequential, empirical way. Very often, teachers do not include problem solutions in the didactics precisely because of the impossibility of providing guided explanation and orientation during problem-solving. From the point of view of the reflexive organization of understanding, the child has to identify kinds of actions and their sequence according to the question of the problem (Nikola \& Talizina, 2001). Memorization is not helpful in such cases. Conditions of the problem always describe some kind of situation, but children are unable to generalize the elements of the situation according to systemic mathematical concepts. The teacher has not only to announce the problem but also to provide the orientation of the analysis of the mathematical relations of the elements of the problem. Knowledge of the context of day-to-day life is not sufficient for this purpose, as constructivist methodology always claims (Carretero \& Castorina, 2012). Specific kinds of intellectual actions are necessary as are operations with scientifically generalized concepts instead of concrete interpretation of the words of the problem (Talizina, 2009). The level of difficulty of the problem depends also on the logical structure of the problem (Rosales, Orrantia, Vicente, \& Chamoso, 2008).

Each arithmetic problem has a final question, where the answer represents the goal of the problem. To answer this question (or a sequence of questions) it is necessary to accomplish reflexive analysis of the data and conditions in order to obtain necessary and sufficient information about mathematical relationships and logic formulas. Mathematical relations are not equal to contextual day-to-day relationships. This point is never explained to children, at least in the traditional way of teaching in Mexico. The consequence is that the pupils, in the best cases, deal with 
the concrete words of the text of the problem and not with the mathematical and logic content of the problem. In the worst cases, children are unable to understand even the concrete texts of the problem. This is another huge problem for teaching and learning progress. The methodology of the teaching of language and the work with texts and comprehension in primary school should be essentially modified (Solovieva, Lázaro, Rosas, Quintanar, Escotto, \& Sánchez, 2014; Solovieva, 2013; Solovieva \& Quintanar, 2010). We are convinced of the strong relationship between the capacity to solve problems in mathematics and the successful acquisition of linguistic abilities by children.

In order for children to operate correctly with the data in problems, it is necessary to provide an orientation attitude and oriented activity in respect to the mathematical content. Such a point of view does not appear naturally and spontaneously, as constructivism might claim. Constant assessment of children's abilities does not help in understanding their difficulties. Only a formative process provides an essential and general understanding of the way that children learn at school (Galperin, 1959a2011). Oriented activity is a functional part of children's intellectual activity in general, which needs to be formed with specific content (Galperin, 1957/2011). Only with the help of the data of oriented activity, instead of passive perception and repetition of the verbal part of the problem, can a child create a general scheme for solving problems of the same kind and only for each concrete problem. Only after such oriented activity is it possible to pass on to the search for arithmetic operations (Luria, 1980; Tsvetkova, 1999). As for problem solution, it is necessary to work with the process of orientation before passing on to the realization of operations.

The traditional way of teaching mathematics starts and finishes with arithmetic operations. Our essential interest was to show a way of creating and applying the methodology of the analysis of teaching and learning activity in the real context of the day-to-day teaching of mathematics in a small private school. The goal of our research was to show the possibility of using this methodology as a unique process. Such analysis of the activity of problem solution permitted us to propose content for guided orientation and for steps to problem solution with the group of Mexican schoolchildren.

Our study included descriptive and qualitative research, which assumed that teaching is a process of the formation of learning. The methodological and theoretical background of our research was the theory of the learning process as a divided and shared activity between teacher and pupils (Leontiev, 2003; Talizina, $2000,2009)$ together with a psychological conception of the formation of mental concepts by steps (Galperin, 1959a/2011, 1957/2011). According to activity-theory methodology, it is possible to have a directed and oriented model of teaching with the conscious and reflective participation of children in the process of solving mathematical problems. In our research, the children became active participants in this process. Collective forms of guided activity were proposed for orientation toward and solution of problems. The whole content of knowledge was systematized according to the identification of general initial concepts (the problem and its elements) and of the essential kinds of intellectual actions with numbers in which such concepts might be included (Davídov, 1996). 


\section{Method}

\section{Participants}

The participants of the study were pupils in the second grade of a private primary school in the city of Puebla, Mexico. They had medium-low social living conditions. The class included four regular pupils with an average age of 7.25 years. The children had no clinical history and had never repeated a grade. All pupils showed sufficient abilities in reading and writing and presented no learning disabilities. An understanding of number concepts and elementary arithmetic operations were the prerequisites that had been established previously. All the children took part in most of the formative sessions, and none ever lost more than three consecutive sessions.

\section{Formative process}

The formative process was used to organize the teaching. We understand such an experiment as a continuation of the genetic causal method proposed by Vygotsky and developed afterward by his followers (Leontiev, 2003). The formative process consists in the organization of the qualitative interaction between the experimenter and the participants. This interaction is not of a spontaneous nature; all levels and types of interaction are previously planned. The plan of action corresponds to the necessities of formation in the stages of the methodology (Galperin, 1959a,b/2011, 1957/2011) and to the content of the problem-solving activity.

At the same time, the concrete forms of communication among the teaching and learning processes are dynamic interactions that provide shared, guided activity within the dialogical involvement of all participants in the joint activity. The formative process always takes into consideration parameters established according to the goals of formation and the concrete necessities of real educational practice (Leontiev, 2003). The experimenter has to know perfectly the content, the structure, and the features of the activity, which are being formed in participants (Solovieva, 2013; Nikola \& Talizina, 2001; Talizina, 2000).

Qualitative analysis of the obtained data and of the teaching process was accomplished during and after the research. The initial and final assessments of the children's activity were made on the bases of the structure of problem-solving activity. Such elements were identification of final and sequential questions, steps, the unit of measurement and conversation of data, operations. Specific difficulties and mistakes were analyzed and quantified for each element before and after the formative experiment.

\section{Formative program}

The goal of the program was to provide orientation for the intellectual activity of problem solution in collaboration with an adult and other children. For this purpose, problem solution was divided into a sequence of external, collective intellectual actions that helped to solve the problems and to answer the final questions. The intellectual actions of the program were completed at perceptive and verbal external levels, according to the conception of the formation of mental actions by stages 
(Galperin, 1998). The program was carried during 30 collective classes of 1 hour each when the college was in session and included a total of 344 simple and complex mathematical problems. The program included the following general stages:

1. Presentation of orientation for the process of problem solution, discussion of the contents of the problems, differentiation of the verbal and numeric aspects of the problems, identification of the steps for solution and elaboration of orientation cards for the steps.

2. Solution of simple problems with the help of orientation cards. Explanation of sufficient data, relevant and irrelevant data, and insufficient data for answering the final question.

3. Solution of complex problems with the help of orientation cards. Identification of sequential questions. Explanation of the necessity to convert units of measurement to only one unit according to the question. Reflection of the impossibility of numeric operations if the unit of measurement is not the same according to the verbal content of the problems.

4. Creation of own problems in groups. Exchange of the problems for independent solution.

\section{Content of the formative program}

Before starting with solution of the problems, some exercises with accessible verbal content were designed for the children. The problems were presented according to level of difficulty (Luria \& Tsvetkova, 1966/1981) and started from simple problems (only one operation involved) to more complex (more than one operation involved) (Table 1).

Table 1. Examples of problems used during the teaching process

\begin{tabular}{ll}
\hline \multicolumn{1}{c}{ Simple problem } & \multicolumn{1}{c}{ Complex problem } \\
\hline "Our library ... has 40 books divided among & $\begin{array}{l}\text { "Renata and Daniel went to the market and } \\
\text { bought 2 kilos of apples, 300 grams of sugar, } \\
5 \text { stands. If the teacher ... puts the same } \\
\text { quantity of books on each stand, how many } \\
\text { books will we have on each stand?" }\end{array}$ \\
\hline
\end{tabular}

These examples show that the verbal structure of simple problems is not necessarily also simple. We tried to show that the word simple might be used equally for mathematical content and for verbal content of the text of the problem. Within the content of the program, different verbal content was used for working with the same type of mathematical structure: one operation or more than one operation.

Afterward, the general orientation for problem solution was presented to the children. It was explained to them that the problems always involve a day-to-day, ordinary situation. The logic of mathematical solution does not depend on using all presented words, subjects, and objects within the text of the problems. Success 
in solving the problems depends on the possibility of substituting one or more arithmetical (mathematical) operations for part of the descriptions. If it is possible to make such a substitution, a problem might be resolved. If not, the problem might not be resolvable in arithmetical terms. Important concepts in this situation are the concepts of number and of the decimal system. Without such concepts it is impossible to solve the problems or to execute arithmetic operations. Memorization of some data is not specifically useful for solving the problems. Each problem requires analysis of the content. It was explained to the children that the problem pretends not to present all data so that the subject needs to search for some of them. The objective is to answer the final question (series of questions) of the problem. In order to find the answer, it is necessary to follow some steps. Children received orientation cards in order to obtain these steps (Figure 1). The card was always designed together with the children in the group and the steps were discussed reflexively. Each participant had his/her own card, which was used for the solution of each problem. Every procedure was planned by the whole group through collaboration and dialogue. The designation of all steps was guided and supervised by the experimenter and participants and was discussed collectively.

The orientation provided by an adult and the whole work in the group was used to form the following intellectual actions:

1. Design a scheme for the verbal situation expressed in the problem. Identification of the final question and of the elements of the problem are represented by the symbols $M, m, v . \quad(M=$ the magnitude of the object that is measured (modified); $m=$ the unit of measurement; $v=$ the number of repetitions of the same unit of measure).

2. Design a plan for solution of the problem. Identify and compare relationships among the data expressed by the words in the problem $(M=$ ? $m=$ ? $v=$ ?) (Figure 1).
1. Read the problem and find the question.
2. Look for: $\mathrm{M}=$ ? $\mathrm{m}=$ ?, $\mathrm{v}=$ ?
3. Find the operation:
1) $\mathrm{Ma}+\mathrm{Mb}=\mathrm{Mc}$;
3) $M=m \times v$;
2) $\mathrm{Ma}-\mathrm{Mb}=\mathrm{Mc}$;

4. Solve the problem.

5. Have you answered the question?

Figure 1. Orientation card for the solution of the problem

3. Find arithmetic operations that correspond to the operations of the solution. A formula for identifying the unit of measurement and the operations was used. In order to identify each operation properly another orientation card was designed (Figure 2). This card helped to organize the known and the unknown data for each problem. 


\begin{tabular}{|c|c|}
\hline $\begin{array}{l}\text { If the problem involves addition: } \\
\text { a) We need to add } \\
\text { b) We know the Magnitude } \\
\text { c) We know the measure }\end{array}$ & $\begin{array}{l}\text { If the problem involves multiplication: } \\
\text { a) We need to find the Magnitude (M) } \\
\text { b) We know the measure (m) } \\
\text { c) We know the number of times the } \\
\text { measurement was used (v) }\end{array}$ \\
\hline Formula: $\mathrm{MA}+\mathrm{MB}=\mathrm{MC}$ & Formula: $\mathrm{M}=\mathrm{m} \times \mathrm{v}$ \\
\hline If the problem involves subtraction: & If the problem involves division: \\
\hline $\begin{array}{l}\text { a) We need to subtract } \\
\text { b) We know the Magnitude } \\
\text { c) We know the measure }\end{array}$ & $\begin{array}{l}\text { a) We need to find the number of times } \\
\text { the measurement was used (v) } \\
\text { b) We know the measure (m) } \\
\text { c) We know the Magnitude (M) }\end{array}$ \\
\hline Formula: $\mathrm{MA}+\mathrm{MB}=\mathrm{MC}$ & Formula: $\mathrm{v}=\mathrm{M} \div \mathrm{m}$ \\
\hline
\end{tabular}

Figure 2. Orientation card for operations

\section{Results}

The study showed that the children were able to assimilate the orientation that was provided according to the revealed methodology. After the work with the orientation card and its content, different arithmetic problems were presented to the children. The children had to read the problem and identify all the elements according to the card. The card was used during all tasks in the group and was discussed orally. The process of reading, discussing, and solving the problems was carried out as external, guided, collective activity. Each child wrote down the elements of the orientation and the solution. They commented on and discussed all elements of the problem. They had to discover the elements and data of the problem and understand whether each of these elements or some of them were abundant in the problem. Some problems had no solutions, and the children commented on why no solution was possible. They were encouraged to verify each solution in the group. Figure 3 is an example of problem solution by one of the pupils. This task implied the operation of division. The children included in our study did not study

The car covered $98 \mathrm{~km}$ in 8 hours. How many $\mathrm{km}$ did the car cover each hour?

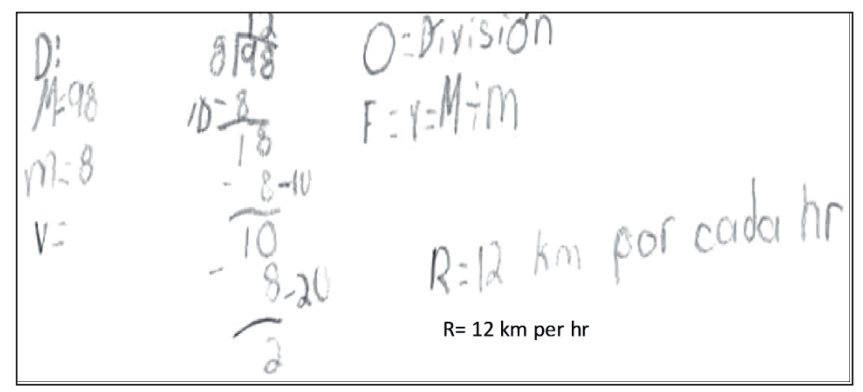

Figure 3. Example of the solution of a simple problem 
the operation of division formally, so they answered with wholes numbers, but they were able to understand the logic of the operations.

Figure 4 shows the problem with operation of multiplication, the children had to convert the measures of time.

Angel's sister eats 6 spoonfuls of porridge in 10 minutes, how many spoonfuls of porridge will she eat in 1 hour?

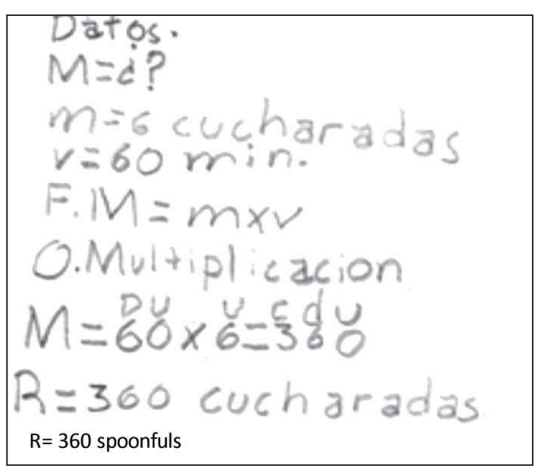

Figure 4. Problem requiring the operation of multiplication

So that they could analyze the data correctly and reflexively, problems with a lack of data and with an abundance of elements were presented to the children. The adult explained that in some cases problems may not have any solution if the data pre-

A group of second graders measured cartoon decorations. The lengths of the decorations were: Buzz Lightyear $-30 \mathrm{~cm}$, Bullseye $-20 \mathrm{~cm}$, Peter Pan $-25 \mathrm{~cm}$, Jessie $-35 \mathrm{~cm}$, Woody $-35 \mathrm{~cm}$, SpongeBob $-25 \mathrm{~cm}$, Blackboard $-15 \mathrm{~cm}$, Patrick Star $-20 \mathrm{~cm}$, Squidward Tentacles $-30 \mathrm{~cm}$, Spiderman $-40 \mathrm{~cm}$, and Sandy Cheeks $-30 \mathrm{~cm}$. Which characters were the highest altogether - the Toy Story characters or the SpongeBob SquarePants characters?

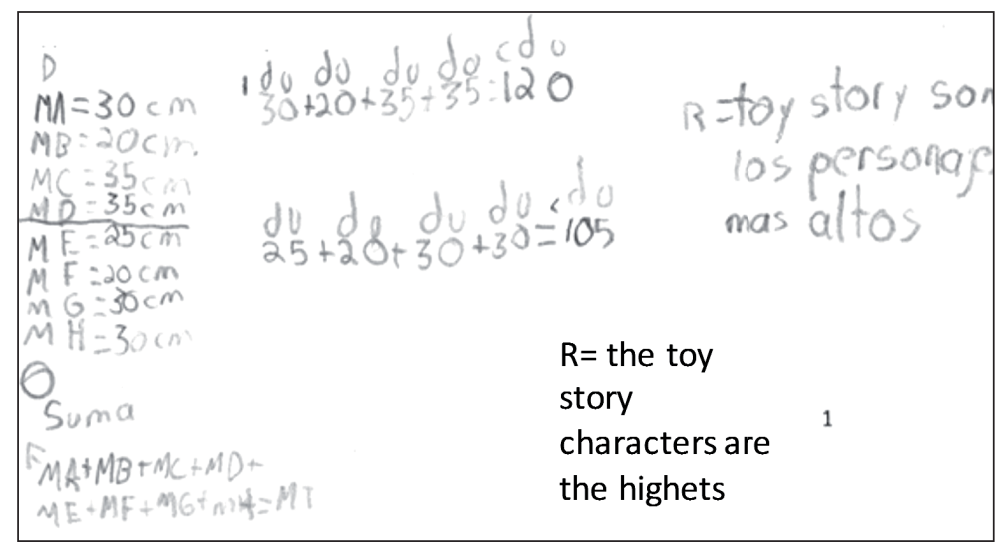

Figure 5. A problem requiring identification of essential and irrelevant data 
sented are not sufficient. In such cases it is not possible to answer the final question. In other cases, the text of the problems may mention details that are not essential for the mathematical solution. Such reasoning helped the children to consciously reflect on and abstract mathematical data from the verbal texts of the problems (Talizina, 2009). Figure 5 is an example of the solution to a problem that required identification of necessary data about characters in the Toy Story films and the SpongeBob SquarePants television series. The children had to distinguish essential characters (e.g., Buzz Lightyear, Bullseye) from irrelevant characters (e.g., Spiderman). Afterward, the children wrote the formulas and solved the problem according to the steps they identified.

While advancing according to the program, the children started to ask questions more quickly and their realization of and verbal comments regarding all steps became unnecessary. After five problem tasks it was unnecessary to mark with a pencil the given data and the final question, and it was possible only to ask the children about the data and the question. This progression shows how external action with many steps became a reduced and automatized intellectual operation (Galperin, 1957/2011, 1959b/2011; Luria, 1980).

After the children solved simple problems (12 lessons), it became possible to include complex problems with more than one operation. In such problems the final questions were not answered in a direct way but by several steps. Each step consisted of answering a sequential question before answering the final question. The children learned how to establish sequential questions according to the problems. The difficulty was that the sequential questions did not appear in the texts of the problems. It was thus necessary to work on the analysis and determination of such intermediate questions. Figure 6 is an example of the problem with two types of units for measuring (decimal numeric system and volume). The children had to organize the data of the problem and convert units of measurement into the same unit (conversion of liters into milliliters).

Daniel collected 150 balls; Axel brought 7 liters of lemon water; Renata put 9 racquets together; Santiago brought 350 milliliters of lemon water. How many toys and milliliters of water did the students have?

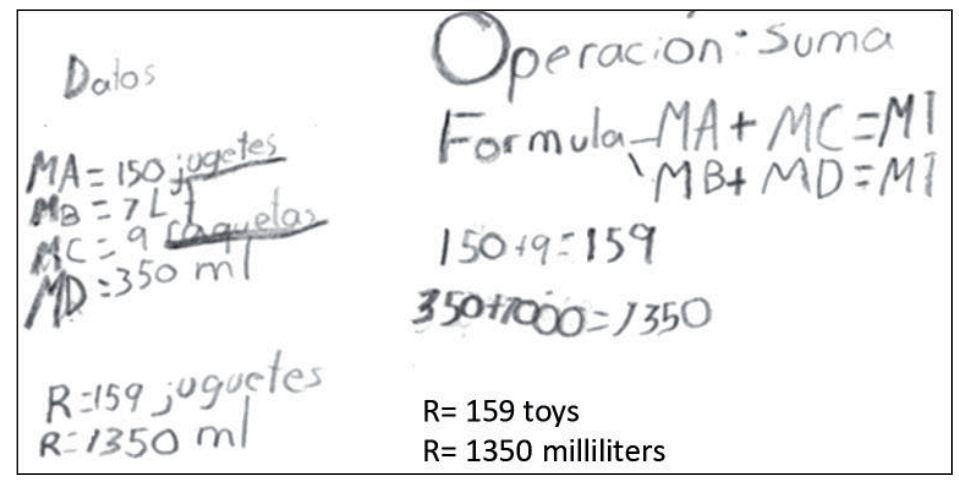

Figure 6. Complex problem with the conversion of a unit of measure (volume) 
Figure 7 shows the conversion of units of measurement of time (conversion of weeks into days).

Renata has found 42 different puzzles that she wants to do in 2 weeks. How many puzzles will she have to do each day?

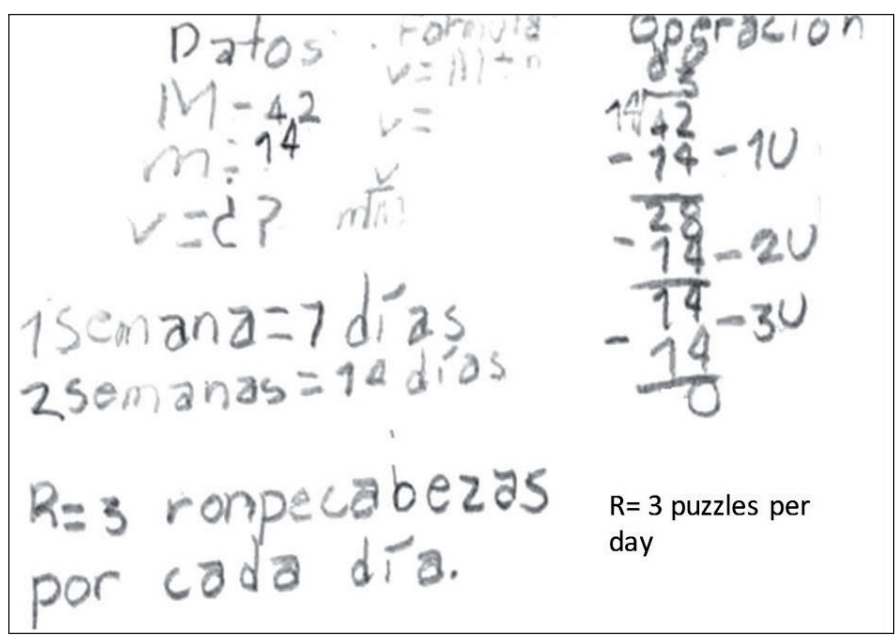

Figure 7. Complex problem with the conversion of units of time

Yola has 40 pencils. She wants to divide all pencils among 10 friends. How many pencils did Yola give to each of the children?

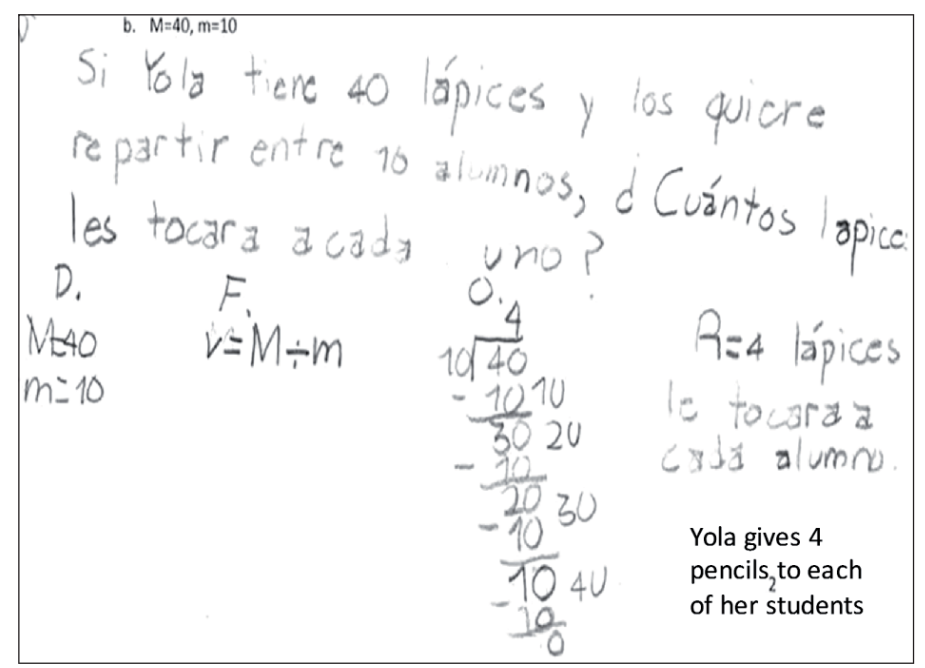

Figure 8. Solution of created problem with the operation of division 
Finally, the creative stage of the program took place. In this stage the children had to create problems with proposed verbal content and numeric relations. For this purpose, orientation with some numeric data was provided to the pupils, while they had to propose and write down a verbal situation that included and mentioned these data. Afterward, the children were able to create all elements (verbal texts and numeric relations) independently. The pupils exchanged problems for independent solution.

Figure 8 shows a problem created by one of the pupils that was solved by another pupil. The given data included magnitude (40) and a unit of measurement (10). The pupils managed to recognize the relationships among the data and chose the operation of division from the contents of the problem.

Figure 9 is an example of the creation of a problem according to given numeric data. A pupil created the verbal text for the problem independently.

Reny bought 50 candies, and her mother gave her 10 candies. Reny ate 25 candies on Monday and she ate 3 candies on Tuesday. How many candies does she have left?

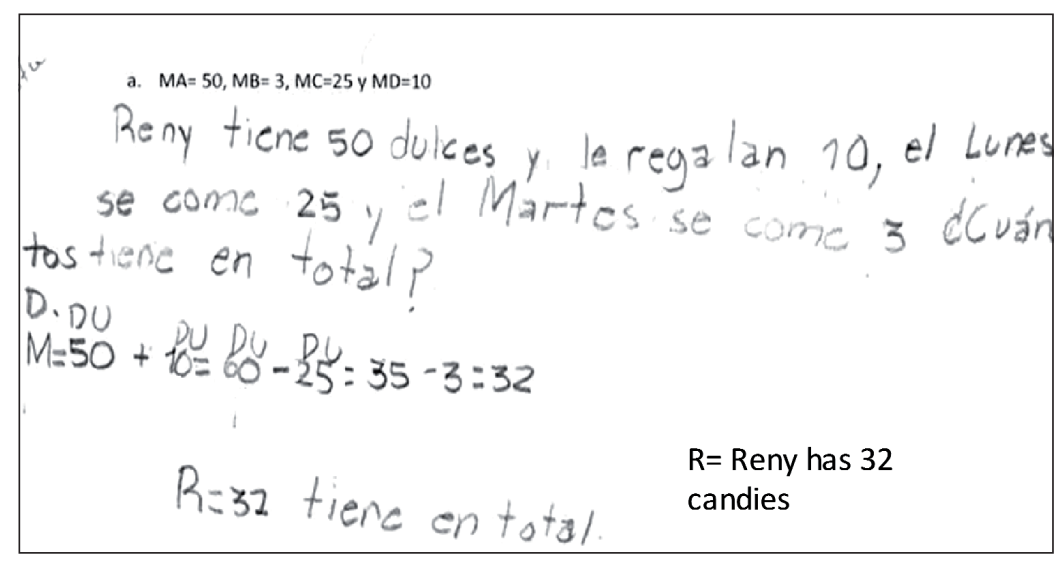

Figure 9. Creation of a problem for the operations of addition and subtraction according to given numeric data.

Finally, the children worked independently to create individual problems according to given numeric data. The children chose the data and proposed different relationships among them. The pupils exchanged their created tasks for solution by other pupils. Figure 10 is an example of such a task.

During the process of working with the program, qualitative analysis of the structure of the elements of the intellectual activity of problem solving was performed. For each element specific errors and difficulties were detected. Table 2 shows the results for an initial assessment according to types of mistakes and difficulties in problem solving. 
My plants receive water 2 times per day. How many times will my plants receive water in 11 days?

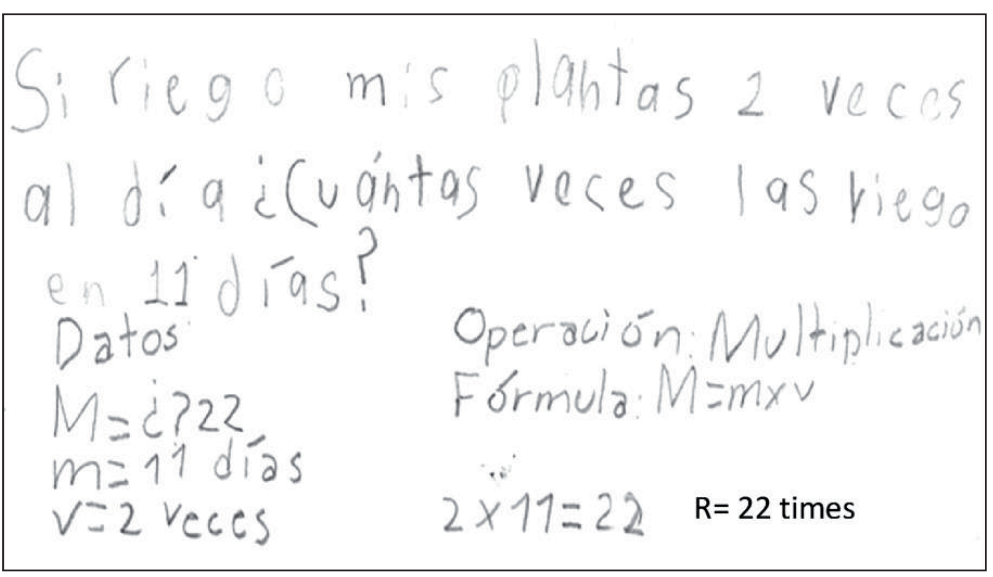

Figure 10. Independent creation of a problem by a pupil

Table 2. Types of errors detected during initial assessment

\section{Element \\ of problem solving}

Identification of the final question

Identification of the relevant data

Performance of the procedure

\section{Types of difficulties and errors}

a) Impulsive answers, anticipation of the answer without paying any attention to the final question.

b) Difficulties in finding the final question.

a) Impossibility of identifying the required unit of measurement.

b) Impossibility of understanding the function of converting the data to only one unit.

c) Difficulties in understanding the relationships between the text of the problem and the mathematical operations.

a) Use of fingers during operations.

b) Difficulties in explaining the steps. Mechanical solution by any kind of arithmetic operation.

c) Difficulties in identifying the concept of digit and the concept of positional unit.

The difficulties and mistakes presented in Table 2 indicate the existence of a developed ability for problem solution. The children intended to solve the problems with no reflection or understanding of the structure and purpose of the problems. Such difficulties disappeared after the participation of the children in the formative program. Figure 11 shows the percentage of correct answers during problem solution before and after participation in the program. The children were able to assimilate the proposed orientation and even started to work without any kind of 
external help. They also were able to create and solve independent problems at the last stage of the program. They performed numeric operations in a correct and rapid way without using their fingers or other material aids.

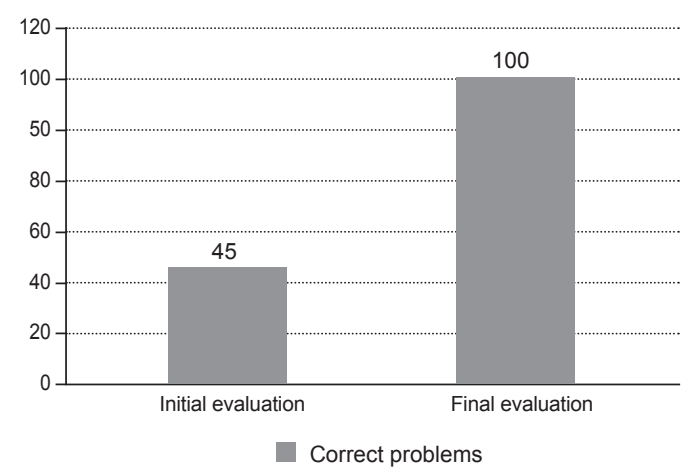

Figure 11. Comparison of correct answers in initial and final assessment, percentage

\section{Discussion}

The results obtained during the formative experiment prove the possibility of formation of the ability not only to solve problems but also to create independent problems. The executions of the children were initially not automatized and were chaotic, with mechanical application of arithmetic operations with no reflection. Later on, the pupils developed the important ability of reflecting on the situation presented in the problems. Our data show that one of the essential elements of such reflection was understanding of the separation of the verbal content of the problem from the numeric relations among the presented data. The absence of such mental separation can be understood as one of the specific difficulties that exist in primary school with the task of problem solution. Another difficulty is the absence of orientation for identifying the final questions and steps and for the obligatory conversion of the data to only one unit of measurement. Final assessment allowed us to observe logic argumentation together with automatization and interiorization of the structural analysis of the content of the problems. Similar results were obtained in previous formative experiments conducted for studying the initial aspects of numeric and logical concepts and operations with Mexican children (Rosas \& Rosas, 2011; Rosas et al., 2014; Solovieva et al., 2010; Solovieva, Rosas, \& Quintanar, 2013; Solovieva et al. 2014; Zárraga et al. 2012) and for solving problems with Russian and Romanian children (Nikola \& Talizina, 2001; Salmina, 2001).

Consideration of the structural components of each task permits the elaboration of an appropriate orientation for the formation of each necessary element. Such an analysis is based on theoretical and methodological findings of activity theory applied to the process of teaching and learning in general (Galperin, 1959a/ 2011; Podolsky, 2010; Talizina, 2000) and specifically to the content of broad mathematical abilities (Butkin, 2001; Talizina, 2001; Volodarskaya; 2001). Such a directed and oriented manner of teaching guaranteed the continuation of systematic knowledge. For example, the children had to identify the relationships of the concept of num- 
ber, the concept of the decimal system, and the positional value of digital and arithmetic operations. Frequently, such aspects of knowledge are presented separately and in different grades so that children may find no connections among these kinds of knowledge. We believe that systematic organization of the content of the matter of mathematics might help to achieve increased understanding and even to elevate the level of motivation in pupils. The possibility not only to solve but also to create and exchange problems is also an important method for elevation of the level of interest and motivation. Our proposal helps to avoid mechanical naming of the parts of numbers as the only way to reflect on the concept of the decimal system. An example of such a method is the constant reading of numbers: for example, the reading of 329 as 300, 20, and 9 without any explanation of the necessity for such a reading. Such "reading" of numbers provokes only confusion and misunderstanding in primary school pupils (Bermejo, 2008; Castaño, 2008).

The method of the gradual formation of mental actions according to activity theory (Galperin, 1959b/2011, 1957/2011; Solovieva, Pelayo, \& Quintanar, 2011; Talizina, 2001, 2009) establishes clear content for the process of teaching. Elaboration of the proper orientation for each school action helps to achieve concrete goals for each task that follows and accompanies the learning process. From this perspective, the role of the teacher and the methods used for teaching are essential for analysis of pupils' success in solving mathematical problems. The contrast of our approach to the learning process and the approach of others can be seen by comparing the proposals for observation of the spontaneous strategies used by pupils and the selection of some of these strategies (Butto \& Gómez, 2014). Another such proposal is analysis of the cognitive styles of children within the learning process (Padilla \& López, 2006; Toledo, Pérez, Riquelme, Hernández, \& Bittner, 2011).

Our results confirm Leontiev's (2003) opinion of the role of culture in cognitive development. Such developments cannot appear directly from culture; specific activity needs to take place to guarantee such development. Only activity can provide the proper type of interaction between teachers and pupils. The object of appropriation must be included as a particular object of joint guided activity. In other cases, it would not be possible to guarantee the success of the learning process. Our results show that oriented joint activity helped our participants to form conceptual and independent strategies for the solution of problems. At the beginning of the study pupils had no such strategy at all. Their strategies were obtained in mutual collaborative situations that had clear meaning and purpose for children. Cognitive sense and real experience (Del Río \& Álvarez, 2011) were obtained not by declaring the necessity of social collaboration but by concrete organization of the situations of problem-solving. A strong part of our study was the realized possibility of creating a specific orientation and of including participants who did not originally show an orientation toward mathematics or problem solution. Reflection on the verbal and numeric content of the problems was achieved through our formative experiment. Our children started to show a positive attitude toward mathematics. They were enthusiastic and interested in the solution of problems and in the creation of their own problems. They were interested in correct answers and in understanding each step of problem solution and creation. They started to verify their actions and to help each other. According to Leontiev (2003), motives might increase within 
oriented activity, and we believe such was the result of our experiment. As one of the children said, "I do not want go home 'til I finish my problem. I have to read it once again and understand the question of the problem."

\section{Limitations}

We are aware that the group of participants in the process of formation was extremely small. The reason for having such a limited number was the fact that the school was completely new at the time of research. However, it is also rather difficult to get permission to use innovative formative procedures in common public educational institutions in Mexico, as in many other countries. Difficulties arise when researchers try to look for control groups in order to compare results with those in traditional teaching institutions. The possibility of comparing obtained results with control groups should become a part also of qualitative research, but it is not always possible in the system of traditional education in Latin America.

\section{Conclusion}

Solution of mathematical problems is not a spontaneous ability that might just appear in the classroom. Specific guided orientation is a useful teaching tool to guarantee proper understanding of the elements of problems and steps for their solution. The method of the gradual formation of mental actions step by step is a strong methodological strategy that may modify positively the analysis of the process of teaching and learning. Reflection by children might be formed together with positive motivation by giving detailed consideration to the organization of the learning process in primary school. Qualitative research in psychology and pedagogy should be considered a useful way for analyzing and reorganizing educational practice.

\section{References}

Ávila, A. (2006). Transformaciones y costumbres en la matemática escolar [Transformations and customs in school mathematics]. México: Paídos.

Álvarez, A. y Del Río, P. (2013). El papel de la educación en el desarrollo: De la escuela a la cultura [The role of education in development. From school to culture]. Cultura y Educación [Culture and Education], 24(2), 137-151.doi: 10.1174/113564013806631309

Bermejo, V. (2008). Un modelo de intervención psicoeducativa en matemáticas- PEIM [A psychoeducational intervention model for mathematics (PEIM)]. Cultura y Educación [Culture and Education], 20(4), 407-421. doi: 10.1174/113564008786542217

Butkin, G. A. (2001). La formación de las habilidades que se encuentran en la base de la demostración geométrica [Formation of the skills that are at the base of the geometrical demonstration]. In N. Talizina (Ed.), La formación de las habilidades del pensamiento matemático [Formation of skills of mathematical thinking], (pp. 151-195). México: Universidad Autónoma de San Luis Potosí.

Butto, C., \& Gómez, L. M. (2014). Las representaciones del sistema numérico decimal indoarábigo en niños de primer grado de primaria [Numeric representation of first grade students in elementary school: A study about progressive levels of development]. Revista Horizontes pedagógicos [Horizons in Education Journal], 16, 9-23. 
Carretero, M., \& Castorina, J. (2012). Cognitive development and education II. Processes of knowledge and specific contents. Madrid: Paídos.

Castaño, J. (2008). Una aproximación al proceso de comprensión de los numerales por parte de los niños: relaciones entre representaciones mentales y semióticas [An approach to the process of understanding numerals by children: Relationships between mental representations and semiotic representations]. Universitas Psychologica [Psychology in University], 3(7), 895-907.

Davydov, V. (1988). Shkolnoe obuchenie i psihicheskoe razvitie [School teaching and psychological development].Moscow: Progress.

Davydov, V. (1996). Teorija razvivajushhego obuchenija [The theory of teaching that leads to the development]. Moscow: INTER.

De Zubiría, J.e (2006). Los modelos pedagógicos, Hacia una pedagogía dialogante [Pedagogical models, Towards a dialogue pedagogy]. Bogotá: Editorial Magisterio.

Del Río, P., \& Álvarez, A. (2011). La actividad como problema de desarrollo. Algunos potenciales educativos del eco-funcionalismo y la psicología histórico-cultural [Activity as a developmental problem. Some educational potentials of eco-functionalism and culturalhistorical psychology]. Cultura y Educación [Culture and Education], 23(4), 601-619. doi: 10.1174/113564011798392442

Galperin, P. Ya. (1998). Psychological activity as objective science (La actividad psicológica como ciencia objetiva). Moscow: Academy of Pedagogical and Social Sciences.

Galperin, P. Ya. (1959a). La formación de los conceptos y de las acciones mentales [Formation of concepts and mental actions]. In L. Quintanar \& Y. Solovieva (Comps.) (2011). Las funciones psicológicas en el desarrollo del niño [Psychological functions in child development] (pp. 80-90). México: Trillas.

Galperin, P. Ya. (1959b). Tipos de orientación y tipos de formación de las acciones y de los conceptos [Types of orientations and training types of actions and concepts]. In L. Quintanar \& Y. Solovieva (Comps.) (2011), Las funciones psicológicas en el desarrollo del niño [Psychological functions in child development] (pp. 76-80). México: Trillas.

Galperin, P. Ya. (1957). Sobre la formación de las imágenes sensoriales y de los conceptos [The formation of sensory images and concepts]. In L. Quintanar \& Y. Solovieva (Comps.) (2011), Las funciones psicológicas en el desarrollo del niño [Psychological functions in child development] (pp. 64-75). México: Trillas.

Ilienkov, E. V. (2009). Shkola dolzhna uchit myslit [School should teach thinking]. Moscow: Russian Academy of Education.

Leontiev, A. N. (2003). Selección de lecturas de psicología del desarrollo [Selected readings of developmental psychology]. Havana, Cuba: S/E.

Luria, A. (1980). Pensamiento y lenguaje [Thought and language]. Barcelona, Spain: MartínezRoca.

Luria, A., \& Tsvetkova, L. S. (1981). La resolución de problemas y sus trastornos [Solving problems and disorders]. Barcelona, Spain: Editorial Fontanella. (Original work published 1966)

Martín, A. (2003). Operación aritmética: La division [Aritmethic operation: division]. Boletín: Las Matemáticas en Secundaria [Bulletin of Mathematics in Secondary School], 25, 1-10.

Nikola, G., \& Talizina, N. (2001). La formación de habilidades generales para la solución de problemas aritméticos [Formation of general skills for solving arithmetic problem]. In N. Talizina (Ed.), La formación de las habilidades del pensamiento matemático [Formation of skills of mathematical thinking], (pp.87-151). México: Universidad Autónoma de San Luis Potosí.

Padilla, V., \& López, E. (2006). Implementación de una red neural para estilos cognitivos y de aprendizaje: Implicaciones educativas [Neural net implementation to recognize cognitive 
and learning styles: Educational implications]. Enseñanza e Investigación en Psicología [Education and Research in Psychology], 11(2), 239-254.

Planea. (2015). Resultados nacionales 2015 de $6^{\circ}$ de primaria y $3^{\circ}$ de secundaria, Lenguaje y comunicación, Matemáticas [National results 2015 6th primary and secondary 3rd, Language and Communication, Mathematics]. Retrieved from http://www.inee.edu.mx/index.php/ planea

Podolsky, A. (2010). P. Galperin's theory of planned stage-by-stage formation of mental action as a tool to improve teaching/learning activity. In P. Aunio, M. Jahnukainen, M. Kalland, \& J. Silvonen, Piaget Is Dead, Vygotsky Is Still Alive, Or? (pp. 223-244). Helsinki, Finland: Finnish Educational Research Association.

Rosales, J., Orrantia, J., Vicente, S., \& Chamoso, J. (2008). La resolución de problemas aritméticos en el aula. ¿Qué hacen los profesores cuando trabajan conjuntamente con sus alumnos? [Arithmetic problem solving in the classroom: What do teachers do when they work jointly with students?] Cultura y Educación [Culture and Education], 20(4), 423-439. doi: $10.1174 / 113564008786542253$

Rosas, Y., \& Rosas, D. (2011). Formando conceptos y transformando vivencias [Formation of concepts and transformation of experiences]. Entre Maestros [Among Teachers], 11(38), 1019.

Rosas, Y., Solovieva, Y., \& Quintanar, L. (2014, June). Formación de las acciones de multiplicación y división en la escuela primaria [Formation of the actions of multiplication and division in the elementary school]. Poiésis, 83-101.

Salmina, N. (2001). La enseñanza de las matemáticas en la escuela primaria [Teaching mathematics in elementary school]. In N. Talizina (Ed.), La formación de las habilidades del pensamiento matemático [Formation of skills of mathematical thinking] (pp. 40-87). México: Universidad Autónoma de San Luis Potosí.

Salmina, N., \& Filiminova, O. (2010). Problemas en el aprendizaje de las matemáticas básicas y su corrección [Problems in learning basic math and their correction]. Puebla, México: Instituto Universitario de Estudios Avanzados.

SERCE. (2009). Aportes para la enseñanza matemática [Contributions to mathematics teaching]. Santiago, Chile: Latin American Laboratory for the Assessment of the Quality of Education.

Solovieva, Y. (2013). El desarrollo desde el enfoque histórico-cultural: Investigaciones educativas en España y México [Development from a historical-cultural conception: Presentation of educational research in Spain and Mexico]. Cultura y Educación [Culture and Education], 25(2), 131-135. doi: 10.1174/113564013806631291

Solovieva, Y., Lazaro, E., Rosas, Y., Quintanar, L., Escotto, A., \& Sánchez, G. (2014). Mathematics acquisition in Mexico: Research on techaing, acquisition difficulties, and correction. Psychology and Neuroscience,7(4), 481-491. doi: 10.3922/j.psns.2014.4.07

Solovieva, Y., Lázaro, E., \& Quintanar, L. (2013). Evaluación de las habilidades matemáticas previas en niños preescolares urbanos y rurales [Assessment of previous mathematical abilities in urban and rural preschool children]. Cultura y Educación [Culture and Education], 25(2), 199-212. doi: 10.1174/113564013806631336

Solovieva, Y., Lázaro, E., Rosas, Y., Quintanar, L., Escotto, A., \& Sánchez, G. (2014). Mathematics acquisition in Mexico: Research on teaching, acquisition difficulties, and correction. Psychology and Neuroscience, 7(4), 481-491. doi: 10.3922/j.psns.2014.4.07

Solovieva, Y., Ortíz, G., \& Quintanar, L. (2010). Formación de conceptos numéricos iniciales en una población de niños mexicanos [Formation of numeric concepts in Mexican school children]. Cultura y Educación [Culture and Education], 22(2), 329-344. doi: $10.1174 / 113564010804932157$ 
Solovieva, Y., Pelayo, H., \& Quintanar, L. (2011). Método para la formación de la lectura diseñado desde las propuestas de L. S. Vygotsky [Method for forming reading proposals designed from L. S. Vygotsky]. Entre Maestros [Among Teachers], 11(38), 58-67.

Solovieva, Y., \& Quintanar, L. (2010). El desarrollo del niño y los métodos de enseñanza [Child development and teaching methods ]. Elementos [Elements], 79, 329-344.

Solovieva, Y., Rosas, Y., \& Quintanar, L. (2013). Symbolic representation for introduction of concept of decimal system in Mexican school children. International Education Studies, 6(10), $102-111$.

Talizina, N. (2000). Manual de psicología pedagógica [Handbook of pedagogical psychology]. México: Universidad Autónoma de San Luis Potosí.

Talizina, N. (2009). La teoría de la actividad aplicada a la enseñanza [The activity theory applied to teaching]. Puebla, México: Benemérita Universidad Autónoma de Puebla.

Toledo, H., Pérez, E., Riquelme, V., Hernández, Z., \& Bittner, V. (2011). Evaluación de los intereses y estilos cognitivos de aprendizaje en ciencia en alumnos de $7^{\circ}$ y $8^{\circ}$ año de enseñanza básica y $1^{\circ}$ y $2^{\circ}$ de educación media de la provincia Llanquihue [Assessment of interests and cognitive styles of learning in science in students 7 th and 8th years of teaching basic and 1st and 2nd of teaching secondary in the province of Llanquihue]. Journal for Educators, Teachers and Trainers, 2, 39-48.

Tsvetkova, L. (1999). Neuropsicología del intelecto [Neuropsychology of intellect]. Havana, Cuba: UAEM.

Vicente, S., Dooren, W., \& Verschaffel, L. (2008). Utilizar las matemáticas para resolver problemas reales [Using mathematics for solving real problems]. Cultura y Educación [Culture and Education], 20(4), 391-406. doi: 10.1174/113564008786542235

Volodarskaya, I. A. (2001). La formación de las habilidades generalizadas del pensamiento geométrico [Formation of generalized geometric thinking skills]. In N. Talizina (Ed.), La formación de las habilidades del pensamiento matemático [Formation of skills of mathematical thinking] (pp. 195-246). México: Universidad Autónoma de San Luis Potosí.

Zárraga, S., Quintanar, L., García, M., \& Solovieva, Y. (2012). Formación de las habilidades matemáticas básicas en preescolares mayores de una comunidad suburbana [Formation of matematics habilities in preescolar children of the suburban zone]. Revista Educacao e Filosofia [Journal of Education and Philosophy], 26, 157-178.

Original manuscript received October 30, 2015 Revised manuscript accepted April 02, 2016

First published online September 30, 2016 